\title{
Exploring Critical Quality Factors in Engineering Education: A Students' Perspective
}

\author{
Santoshi Sengupta ${ }^{1}$, Arpita Sharma ${ }^{2}$ \\ Assistant Professor, Department of Humanities and Social Sciences, Jaypee Institute of Information Technology, \\ Noida \\ ${ }^{1}$ santoshisengupta@gmail.com, ${ }^{2}$ send2arpi@gmail.com
}

\begin{abstract}
Indian engineering education has been subjected to swift and radical change over the recent years, especially with the increase in private institutes across the length and breadth of the nation. This paper aims at determining the gap between expectations and perceptions of engineering education from the perspective of students. Servqual instrument was used to gather data from 189 students from new age private engineering institutes. Reliability tests, correlation and regression were done to ensure the validity of the data collected. Further, gap analysis was done to check out for the existing gaps. Correlation was also done to find out the relationship between the dimensions of education quality and overall satisfaction of the students, and finally regression was done to find out the actual determinants of students' satisfaction. The is helpful for both engineering institutes and other academicians as it helps in disentangling the perceptions about education quality from the students' point of view. This will largely help the upcoming private institutes to design their services in the best possible manner.
\end{abstract}

\section{Keywords}

Education, quality, engineering, students, satisfaction

\section{Academic Discipline and Sub-Disciplines}

Education, Service

\section{SUBJECT CLASSIFICATION}

Education

\section{TYPE (METHOD/APPROACH)}

Survey/Interview

\section{Council for Innovative Research}

Peer Review Research Publishing System

Journal: International Journal of Management \& Information Technology

Vol. 6, No. 1

editor@cirworld.com

www.cirworld.com, member.cirworld.com 


\section{INTRODUCTION}

Engineering education in India started during the British era and focused mainly on civil engineering. Some of the earliest engineering colleges established and present today are: The Engineering College at Roorkee (1847), Poona Civil Engineering College at Pune (1854), Bengal Engineering College at Shibpur (1856), Banaras Hindu University (1916) and Harcourt Butler Technological Institute, Kanpur (1920). In 1945 the Sarkar Committee was appointed to suggest options for advanced technical education in India. The Sarkar committee recommended the establishment of higher technical institutes based on the Massachusetts Institute of Technology in the four regions of India. This resulted in the setting up of the five Indian Institutes of Technology at Kharagpur (1950), Bombay (1958), Kanpur (1959), Madras (1960) and Delhi (1961) (Delhi was added on to the original four). The All India Council for Technical Education was set up in 1945, to oversee all technical education (diploma, degree and post-graduate) in the country.

Since then there has been a significant increase in the number of engineering institutions and in student output. A mechanism for accreditation (National Board of Accreditation) and an umbrella agency, the All India Council of Technical Education (AICTE) has also been set up to monitor and control the quality of engineering education in India (Bannerjee and Muley 2007). However, with the establishment of a large number of institutes, the engineering education has become more of a "product" with varying customers and stakeholders. The institutes are facing tremendous competition and are under immense pressure to become more responsive to customer needs and gain an upper edge. According to Sahney et al. (2008) the educational institutions are becoming more efficient, effective and customer-centric. The institutes are aiming to improve the quality of their services, achieve competitive advantage and move on a path of academic excellence.

In the current socioeconomic context, the education sector has become increasingly more important, revealing the need to know and study the particularities of its operations and services and to institute specific management methodologies that fit its context and specificity. There is an analogy in a transformation system and educational system, wherein both have inputs, processes and outputs. Inputs are the students that undergo a process called education and come out as professionals. This transformation system can be examined and evaluated so as to identify the quality components, the implementation of which could lead to the application of TQM in education. It is essential to identify what a student wants and what an institute delivers. It is then vitally important to compare the perceptions of the students relating to these requirements and characteristics with their expectations and thus, determine "service quality" of education. However, it is equally critical to understand that service processes in education are different from manufacturing processes, especially due to their intangible nature and the direct participation of students. For successful delivery of the services associated with education, institutes make every effort to meet their needs and exceed their expectations. The SERVQUAL scale is one of the tools that can help in this sense. Valuing the widespread usage of servqual scale to assess the quality of services in almost every sector, this study attempts to analyze the gap between expectations and perceptions of students in engineering education with special reference to private colleges.

This paper presents an empirical study on the application of SERVQUAL from the students' perspective, based on a theoretical foundation, together with analysis and results. It outlines the results of a study conducted on students to obtain a student perspective on the quality of selected engineering educational institutions. The various variables to study the gap were identified from a pilot study, which itself was based on a literature review. The SERVQUAL process was applied to identify the gap between perception and expectation and determine the level of service quality.

\section{LITERATURE REVIEW}

Excellence in quality education has been well researched and documented with number of researchers defining what constitutes quality in education. According Oliveira and Ferreira (2009) "Quality in services such as education is often defined as a customer satisfaction index for any service and this satisfaction can be measured by any criteria". Quality in services such as education, infact is often judged according to perceived satisfaction. According to Grönroos (2005), perceived quality is determined "by the gap between expected quality and experienced quality", that is, it is the difference between client perceptions and expectations. According to Coelho (2004), quality is only measured at the end of the process, that is, when the service has been concluded, and there is no way to change client perception regarding the service received. Thus, most definitions of quality in education are customer focused, i.e. meeting or exceeding customer's expectations of education (Parasuraman et al., 1985), with an emphasis on identification of relevant bases and measurement criteria to use in evaluating quality. A widely accepted view on quality is the degree to which stakeholders' needs and expectations are consistently satisfied. However, with the educational system having various customers and stakeholders, formulating a single, comprehensive definition that can integrate the interests of all the customers and stakeholders becomes challenging. With numerous customers and stakeholders, both internal and external to the system, with their own demands and expectations, the identification of design characteristics that would impact the processes part, integrate the interests of the various stakeholders and lead to customer dynamics of what would constitute a success model (Sahney et al. 2008).

One of the most successful and prominently used models for gauging the quality of services provided by any organization is SERVQUAL. According to Salome and Michael (2005), SERVQUAL is the method that assesses client satisfaction as a result of the difference between expectation and the performance obtained. While Zeithaml et al., (1990) states that SERVQUAL is universal and can be applied to any service organization to assess the quality of services provided. Higher education institutions are also in search of improvements in teaching service quality to satisfy the expectations of their students and the 
market. However, since education services have very particular characteristics, the SERVQUAL model must be adapted according to the most important determining factors: reliability, tangibility, responsibility, security and empathy, as proposed by Parasuraman et al., (1985). These dimensions are briefly commented below (Bateson and Hoffman, 2001; Lovelock, 2001):

- Reliability: is the company reliable in providing the service? Does it provide as promised? Reliability reflects a company's consistency and certainty in terms of performance. Reliability is the most important dimension for the consumer of services;

- Tangibility: how are the service provider's physical installations, equipment, people and communication material? Since there is no physical element to be assessed in services, clients often trust the tangible evidence that surrounds it when making their assessment;

- Responsibility: are company employees helpful and capable of providing fast service? It is responsible for measuring company and employee receptiveness towards clients;

- Security: are employees well-informed, educated, competent and trustworthy? This dimension encompasses the company's competence, courtesy and precision; and

- Empathy: this is the capacity a person has to experience another's feelings. Does the service company provide careful and personalized attention?

Since these elements have a highly subjective factor linked to the person who perceives the service and are intangible in nature, it is quite difficult to measure the quality of service. Aimed at solving this problem, Parasuraman et al., (1985) developed a methodology in which there is a comparison between several orders of expectations and perceptions of service quality by the consumer. The Servqual scale (questionnaire) has two sections: one to map client expectations in relation to a service segment and the other to map perception in relation to a certain service company (Fitzsimmons and Fitzsimmons, 2001). The original SERVQUAL scale uses 22 questions to measure the five dimensions of service quality: reliability, tangibility, security, empathy and responsibility. Badri et al., (2005) underscore some services in which the SERVQUAL model can be applied, including the Higher education service, The majority of the work to date has attempted to use the SERVQUAL (Parasuraman et al., 1985; 1988) methodology in an effort to measure service quality (e.g. Brooks et al., 1999; Chaston, 1994; Edvardsson et al., 1997; Lings and Brooks, 1998; Reynoso and Moore, 1995; Young and Varble, 1997; Sahney et al., 2004).

The aim of this study involves the use of SERVQUAL instrument in order to ascertain any actual or perceived gaps between expectations and perceptions of the education offered from the perspective of students.

\section{RESEARCH METHODOLOGY}

The study was exploratory and diagnostic in nature with an emphasis on discovery of insights and ideas. The study was confined to selected private engineering institutions offering graduate and post-graduate professional degrees/diplomas. An attempt was made to conceptualize and operationalize a quality construct specific to engineering education based on research into service quality (Zeithaml et al., 1985; Cronin and Tay|lor, 1992, 1994; Teas, 1993, 1994; Parasuraman et al., 1994a, 1994b; Owlia and Aspinwall, 1998). The expectations and perceptions of students have been conceptualized from previous literature (Oliveira and Ferreira 2009) and have been categorized under five constructs. The terminology has been borrowed from Oliveira and Ferreira (2009) and the constructs are named as -reliability, tangibility, security, responsiveness and empathy. Based on literature review, and with particular emphasis on the various models and performance indicators in education, the variables and the items for the study were conceptualized. These items were then tested to examine the validity and reliability of the scale during the pilot study stage so as to enable a quantitative and statistically proven identification of quality of engineering education.

The servqual questionnaire adapted to suit higher education by Oliviera and Ferreira (2009) was adopted for this study. The adaptation of a questionnaire should be done within a logical sequence derived from an improvement process (Oliveira and Ferreira 2009). The adapted questionnaire was administered to 189 students from private engineering institutes. To test the validity of the instrument, cronbach alpha test was conducted. Cronbach alpha was calculated to measure the internal consistency and reliability of the instrument. The overall cronbach of the instrument came out to be 0.866 , thus the instrument was considered reliable for the study. Reliability was also calculated for the two parts of the instrument i.e. expectations part and perceptions part. The cronbach alpha for the expectations part and perceptions part came as 0.905 and 0.822 respectively. This was followed by correlation test wherein, various constructs of quality of engineering education were checked for their correlations with one another. After the test, the constructs proved to be positively correlated to one another (Table I).

$\mathrm{H} 1$. There is a positive correlation between the various constructs relating to quality of engineering education.

The five constructs relating to quality of engineering education namely tangibility, reliability, responsiveness, assurance and empathy were subjected to a correlation analysis. The constructs were found to correlate with one another (see Table I). Thus the null hypothesis was rejected and it was proved that there is a positive correlation between the various constructs. 
Table I: Correlation analysis between constructs $(\mathrm{N}=189)$

\begin{tabular}{lccccc}
\hline $\begin{array}{l}\text { Constructs/ } \\
\text { Dimensions }\end{array}$ & Tangibility & Reliability & Responsiveness & Assurance & Empathy \\
\hline Tangibility & 1.000 & $.507^{* *}$ & $.250^{*}$ & $.491^{* *}$ & $.285^{*}$ \\
Reliability & & 1.000 & $.569^{* *}$ & $.625^{* *}$ & $.580^{* *}$ \\
Responsiveness & & & 1.000 & $.666^{* *}$ & $.509^{* *}$ \\
Assurance & & & & 1.000 & $.663^{* *}$ \\
Empathy & & & & 1.000 \\
\hline
\end{tabular}

Notes: * Correlation is significant at the 0.05 level (2-tailed); ${ }^{*}$ Correlation is significant at the 0.01 level (2-tailed)

\subsection{Data analysis}

Two software packages - SPSS 16.0 version and Microsoft Excel were used for the analysis of the data. The statistical analysis for conducting the analysis for service quality in education from students' perspective was descriptive as well as inferential, and included multivariate techniques through correlation analysis. The scale's reliability was assessed by calculating the Cronbach's alpha; for analyzing the quality of education the mean and the standard deviation scores for each of the items were calculated for the perception level $(P)$ and the expectation levels $(E)$. The mean perception scores were compared to the mean expectation scores for the various customer requirements and the design characteristics so as to identify the Gap scores (perception-expectation, P-E = Gap).

\subsection{Relevance of the gap (perception minus expectation) as a predictor of education quality}

The relevance of the gap (perception minus expectation) as a predictor of education quality was analyzed before carrying out the analysis. Simple linear regression analysis was carried out, with perception as a predictor and the gap (perception minus expectation) as the dependent variable. For the quality of education from students' perspective, there proved to be a highly significant correlation with a p-value less than 0.01 . The value of $R^{2}$ was 0.67 and this indicated a goodness-of-fit of the model. The value of $F$ was large (17.943) and with $p$-value for $F$ being less than 0.01 , thus, the linear relation was highly significant (Table II). Based on the results obtained, it can be concluded the perception minus expectation gap is a predictor of service quality for education from the students' perspective.

Table II. Relevance of the perception minus expectation gap as a predictor of quality of education

\begin{tabular}{lccccc}
\hline & Pearson's Correlation & Significance & $\mathbf{R}^{2}$ & $\mathbf{F}$ & Significance \\
\hline $\begin{array}{l}\text { Perception } \\
\text { Gap in quality }\end{array}$ & 0.819 & 0.000 & 0.67 & 17.94 & 0.000 \\
\hline
\end{tabular}

\subsection{Gap analysis and findings}

The differences in the gap scores (perception minus expectation, $P-E=$ Gap) for education quality was studied for the student sample. The respondents were asked to respond on a scale of seven, their degree of expectations - from "low" to "high" and their degree of actual experience, again on a scale of seven - from "poor" to "excellent". The mean and the standard deviation scores for each of the items was calculated for the perception level $(P)$ and the expectation levels $(E)$ and then the gap $(P-E)$ was calculated. The mean perception scores were compared to the mean expectation scores for the various constructs of quality of engineering education so as to identify the gap scores (perception - expectation, $\mathrm{P}-\mathrm{E}=\mathrm{Gap}$ ).

The coefficient $\alpha$ values for the expectation sub-scales ranged from 0.641 to 0.798 while those of perception sub-scales ranged from 0.698 to 0.828 , indicating that the scale was internally consistent (Cronbach, 1951). The item-to-total correlation for individual items for both the perception as well as the expectation sub-scales was greater than the 0.35 cut of value (Nunnally, 1978). In order to check the predictive validity, the individual item scores for the perception, expectation and gap 
scores were added together to get the scores for each and these were correlated. The correlated scores were statistically significant (Table III).

Table III. Assessment of predictive validity: correlation between the perception, expectation and gap scores for quality of engineering education $(\mathrm{N}=189)$

\begin{tabular}{lccc} 
& Perception & Expectations & Gap Scores \\
\hline Perception & 1.00 & $0.463^{\star *}$ & $0.819^{\star *}$ \\
Expectations & & 1.00 & \\
Gap Scores & & & 1.00 \\
\hline
\end{tabular}

The items in each construct/dimension were subjected to univariate analysis through the mean and standard deviation scores for perception and expectation. The results of the two sections i.e. expectations and perceptions were compared to arrive at a parameter for each of the questions and also for each of the five dimensions, that is, the final score was generated by the difference between the students' perceptions and expectations. We underscored that a negative result must be viewed as an opportunity for improvement and not as a simple problem, whereas a positive score may be a reason to feel good and can be subjected to further improvement.

Items 1 to 4 refer to the tangibility dimension, which obtained an overall average of 1.125 and the surprising thing was that the gap was positive. The dimension of tangibility measures the physical attributes associated with the engineering education in the new age private institutes. The gap in this dimension was positive as against the rest of the dimensions which had negative gaps. This suggests that as far as tangibility is concerned, the new age private engineering institutes are investing a lot on the infrastructure, equipments and physical attributes of the institute. The expectation of students in relation to this dimension was high in items 1 and 4, and the corresponding perception was higher than their expectations. In fact all the items i.e. modern equipments, visually appealing physical facilities, materials associated with education and presentation of employees (clothes and cleanliness) had a positive difference implying that perception surpassed the expectations of the students. This led to a positive difference in this dimension, which indicates that the new age private engineering institutes in India are doing an astounding job in setting up attractive infrastructure and focusing on the tangible features of the engineering education.

The reliability dimension was analyzed in items 5 to 7 , which obtained an overall average of -1.34 , the highest difference among all the dimensions. Item 6 that measured the students' expectations from sincere interest of institute towards student's problem received a high expectation of 5.98 but a poor perception score of 3.5 only, due to which it had the highest gap of 1.98 in this dimension as well across all the dimensions. This reveals that the students recognize this issue as essential for the quality of the service provided. Therefore, the institute must consider improving their grievance redressal mechanism especially when it comes to students' matter. Apart from that, promise worthiness of the institute and doing job the right way also received high expectations and relatively low perception score due to which the average gap in this dimension came out to be -1.34. Thus, special attention must be given to this aspect since reliability is the most important dimension for the service consumer (Bateson and Hoffman, 2001; Lovelock, 2001).

Items 8 to 11 of the instrument refer to the responsiveness dimension and its overall average was -0.4 , the least negative difference among the five dimensions proposed by Lovelock (2001). The difference between perceptions and expectations ( $P$ E) for all items in this dimension was negative, revealing there are considerable faults in the service, which are jeopardizing the quality of the service being offered. Minimization of these problems is directly related to the willingness of the institute to help the students.

Items 12 to 15 in the adapted SERVQUAL scale refer to the assurance dimension, which obtained an overall average of 0.835. Item 15 (expectations version) i.e. possess knowledge needed to answer questions obtained the highest average in the entire table with a score of 6.36 showing that the assurance dimension is important for the students who are beginning undergraduate studies. Items like inspiring confidence among the students, feeling of safety in their transactions and politeness among the teachers was regarded important attributes that the students expect from an engineering institute. This dimension had the highest score (5.6) in expectations version and a relatively low score in the perception version (4.77). This corroborates what was said by Zanella et al., (2006), who consider this dimension one of the most important, along with reliability.

The empathy dimension was analyzed in items 16 to 19 , which obtained an overall average of -1.205 , the second highest difference after reliability. The averages for both the expectations and perceptions version did not vary much, but there was a considerable difference between the two. Item 19 i.e. understanding the specific needs of the students had the largest gap -2.4 as the expectation was 5.98 whereas the perception was just 3.58 . In this dimension, the greatest concern is understanding the needs. In the specific case of this survey, it was found that students who come for engineering hail from a wide variety of backgrounds due to which results in a wide spectrum of students as far as their caliber is concerned. Such students expect the 
institute to understand their specific needs regarding education, finance, accommodation and other aspects. These factors certainly influenced this evaluation and it should be seriously considered by the institutes.

The overall average for the five dimensions was -0.531 . This indicates a great opportunity for improvement in the service providing cycle. Tangibles had a positive gap, thus this attribute can be enhanced all the more to transform into 'delighters' from mere 'satisfiers'. Other dimensions should get better so as to stand high in the perception of the students. However, for that to happen, great effort must be made in the following items: showing sincere interest of institute towards student's problem; promise worthiness of the institute; inspiring confidence in the students; and focus on the best service for their students.

Table IV. Service quality/gap analysis for engineering education

\begin{tabular}{|c|c|c|c|c|c|c|}
\hline \multirow[b]{2}{*}{ Item No. } & \multirow{2}{*}{$\begin{array}{l}\text { Constructs/Dimensions } \\
\text { Item Description }\end{array}$} & \multicolumn{2}{|c|}{ Expectation } & \multicolumn{2}{|c|}{ Perception } & \multirow{2}{*}{$\begin{array}{l}\text { Gap } \\
\text { P-E }\end{array}$} \\
\hline & & Mean & S.D & Mean & S.D & \\
\hline & Tangibility & \multicolumn{2}{|c|}{$\alpha=.741$} & \multicolumn{2}{|c|}{$\alpha=.709$} & 1.125 \\
\hline 1 & Modern Equipments & 6.08 & 0.81 & 6.58 & 1.14 & 0.5 \\
\hline 2 & Visually appealing physical facilities & 4.64 & 1.43 & 6 & 1.69 & 1.36 \\
\hline 3 & Presentation of employees (clothes and cleanliness) & 4.62 & 1.73 & 6.2 & 1.35 & 1.58 \\
\hline \multirow[t]{2}{*}{4} & Visually appealing material associated with education & 5.14 & 1.04 & 6.2 & 1.62 & 1.06 \\
\hline & Reliability & \multicolumn{2}{|c|}{$\alpha=.727$} & \multicolumn{2}{|c|}{$\alpha=.792$} & -1.34 \\
\hline 5 & Promise worthiness of the institute & 5.96 & 1.35 & 4.1 & 1.62 & -1.86 \\
\hline 6 & Sincere interest of institute towards student's problem & 5.48 & 1.42 & 3.5 & 1.58 & -1.98 \\
\hline \multirow[t]{2}{*}{7} & Doing job the right way & 4.28 & 1.65 & 4.1 & 1.31 & -0.18 \\
\hline & Responsiveness & \multicolumn{2}{|c|}{$\alpha=.772$} & \multicolumn{2}{|c|}{$\alpha=.828$} & -0.4 \\
\hline 8 & Promise services that are met within deadlines & 4.8 & 1.58 & 4.86 & 1.29 & 0.06 \\
\hline 9 & Willing and available during service providing & 5.44 & 1.16 & 5.18 & 1.27 & -0.26 \\
\hline 10 & Show good will in helping their students & 5.86 & 1.23 & 5.06 & 1.54 & -0.8 \\
\hline \multirow[t]{2}{*}{11} & Willing to explain doubts their students may have & 5.86 & 1.36 & 5.26 & 1.40 & -0.6 \\
\hline & Assurance & \multicolumn{2}{|c|}{$\alpha=.798$} & \multicolumn{2}{|c|}{$\alpha=.803$} & -1.085 \\
\hline 12 & Inspire confidence in the students & 6.06 & 1.04 & 4.18 & 1.79 & -1.88 \\
\hline 13 & Feeling of safety in their transactions with the institutes & 5.3 & 1.43 & 5.4 & 1.53 & 0.1 \\
\hline 14 & Politeness in the teachers & 4.7 & 1.37 & 4.42 & 1.76 & -0.28 \\
\hline \multirow[t]{2}{*}{15} & Possess knowledge needed to answer questions & 6.36 & 0.98 & 5.08 & 1.52 & -1.28 \\
\hline & Empathy & \multicolumn{2}{|c|}{$\alpha=.783$} & \multicolumn{2}{|c|}{$\alpha=.753$} & -1.205 \\
\hline 16 & Convenient business hours for all students & 5.04 & 1.09 & 4.54 & 1.85 & -0.5 \\
\hline 17 & Paying individual attention to each student & 4.38 & 1.71 & 4.2 & 1.54 & -0.18 \\
\hline 18 & Focus on the best service for their students & 6.06 & 1.04 & 4.32 & 1.58 & -1.74 \\
\hline 19 & Understanding the specific needs of their students & 5.98 & 1.06 & 3.58 & 1.72 & -2.4 \\
\hline
\end{tabular}


Further, weights of these five dimensions were also calculated on the basis of responses from the students. To determine the importance of each of the dimensions, respondents were requested to divide 100 points among reliability, assurance, tangibles, empathy and responsiveness. Reliability had the highest weight of 25 out of 100, followed by tangibility, responsiveness, assurance and empathy. Thus gaps were once again calculated, this time, giving weights to the dimension as well. The overall weighted average for the five dimensions was -10.06 (Table V).

Table V: Weighted gap score of the quality of engineering education

\begin{tabular}{lcccc}
\hline Dimensions & Unweighted Gap & Weight & Weighted Gap & Rank \\
\hline Tangibility & 1.125 & 22.00 & 24.75 & $\mathrm{~V}$ \\
Reliability & -1.34 & 25.00 & -33.50 & $\mathrm{I}$ \\
Responsiveness & -0.4 & 19.00 & -7.60 & $\mathrm{IV}$ \\
Assurance & -0.835 & 19.00 & -15.87 & III \\
Empathy & -1.205 & 15.00 & -18.08 & $\mathrm{II}$ \\
\hline Unweighted Servqual Score & $\mathbf{- 0 . 5 3 1}$ & Weighted Servqual Score & $\mathbf{- 1 0 . 0 6}$ & \\
\hline
\end{tabular}

In addition to this, stepwise regression was also run to determine the determinants of overall satisfaction of the students from the quality of education in engineering institute. For this, firstly correlations were calculated between overall satisfaction and the five dimensions/constructs of quality (Table VI) and then regression analysis was run to evaluate the weighted importance of overall satisfaction levels for each of these dimensions in comparison with perception of the overall satisfaction level. All the dimensions of quality of engineering education had statistically significant positive correlation with the students' overall satisfaction from the quality of engineering education.

Table VI: Relationships (Correlation coefficients) of dimensions of quality of engineering education with overall satisfaction ( $\mathrm{N}=189)$

\begin{tabular}{cc}
\hline Dimensions of quality of engineering education & Overall Satisfaction \\
\hline Tangibility & $0.585^{\star \star}$ \\
Reliability & $0.629^{\star *}$ \\
Responsiveness & $0.634^{\star *}$ \\
Assurance & $0.536^{\star *}$ \\
Empathy & $0.590^{\star *}$ \\
\hline
\end{tabular}

** Significant at .01 level.

Next, the regression model of the dimensions that contribute to satisfaction from quality in engineering education was worked out. The regression equation in the model examines the strength of the independent variables in predicting the dependent variable. It was assumed that there is a linear relationship between the dimensions of quality and the overall satisfaction level of students. A stepwise regression was run to eliminate insignificant variables and to form a model, with the dependent variable as overall satisfaction from engineering education and the independent variables as the dimensions of service quality. These five dimensions viz., tangibility, reliability, responsiveness, assurance, and empathy were then put in the model as independent variables and overall satisfaction from engineering education was put as the dependent variable. Only three variables out of five contributed significantly to the equation. The equation which emerged after the process was as follows. Table VII summarizes the determinants of the equation.

$$
Y=0.51+0.423 X_{1}+0.324 X_{2}+0.319 X_{3}
$$

Where,

$$
\begin{aligned}
& Y=\text { Overall Satisfaction of students from engineering education } \\
& X_{1}=\text { Reliability } \\
& X_{2}=\text { Tangibility } \\
& X_{3}=\text { Assurance }
\end{aligned}
$$


Table VII: Determinants of students' satisfaction in engineering education $(\mathrm{N}=189)$

\begin{tabular}{cccc}
\hline \multirow{2}{*}{ Independent Variables } & \multicolumn{2}{c}{ Dependent variable: Overall satisfaction of students } \\
\cline { 2 - 4 } & Beta & Simple r & t-value \\
\hline Reliability & .423 & $0.629^{* *}$ & 4.05 \\
Tangibility & .324 & $0.585^{\star *}$ & 3.65 \\
Assurance & .319 & $0.536^{\star *}$ & 3.43 \\
\hline \multicolumn{4}{c}{ Multiple $R=0.855$} \\
\\
\multicolumn{4}{c}{ R Square $=0.731$} \\
\hline
\end{tabular}

** Significant at 0.01 level

The above equation implies that $73 \%$ of the overall satisfaction of students from the quality of engineering education is explained by dimensions of reliability, tangibility and assurance. The finding shows that improving on the quality of i) reliability i.e. increasing the promise worthiness of the institute, generating sincere interest towards student's problem, and doing job the right way; ii) tangibility i.e. improving the physical features of the institute, making it visually more appealing and iii) assurance i.e. inspiring confidence in the students, making them feel safety in their transactions with the institute, encouraging politeness in the teachers, and ensuring knowledge in the teachers to answer questions can enhance the overall satisfaction of students towards the quality of engineering education.

\section{CONCLUSION}

The technical educational system in India has become conscious of the quality of education being offered by private engineering institutes. In the recent times, a lot of policy changes have taken place as far as private institutes offering engineering course are concerned and thus institutes in a nation like India are interested in tools and techniques which will enable them to measure and improve the quality of education they provide. The quality of engineering education as offered by private institutes, especially in developing countries like India, must be viewed as a strategic issue for social and technological development and also for intellectual growth. The objective of this study was to provide a small contribution towards improving engineering education service by adapting and using the SERVQUAL instrument that, if well used, can generate interesting results for the improvement of engineering education by the private institutes. We underscore that the theoretical reference presented in this paper in a summarized manner played an important role for the researchers, making it possible to adapt the SERVQUAL scale to the reality of educational service processes and applied to students studying an engineering course.

This study demonstrates that a structured quantitative approach to service quality can help an educational institute to understand the factors that the students understand as constituting quality. The gap analysis - which measures the difference between perceived quality and expectation of quality - shows the levels of satisfaction/dissatisfaction with different parts and attributes of the education being offered. There is a degree of confidence in the results owing to the validity and reliability checking that has taken place during the analysis. Wherever a "negative gap" is obtained - the expectation level is higher than the level of perceived quality - there is a significant level of dissatisfaction among the students. This indicates the priority areas for improvement.

The use of Servqual as the survey instrument provided the necessary conditions to conduct this study, proving to be appropriate and generating results with a considerable degree of applicability, although without forgetting scientific rigor. In relation to application of the scale adapted to measure the quality of engineering education as offered by private institutes from the perspective of students, we observed that the reliability dimension had the largest gap, with an overall average of -1.34 (unweighted) and -33.50 (weighted), followed by empathy, assurance and responsiveness, thus indicating the perceptions are below expectations and there are faults in the service that are generating unsatisfactory results among the students. Tangibility alone had positive difference, which naturally is true as private institutes nowadays invest a lot on their infrastructure and aesthetics of the premises. One can observe interesting results for the potential use of quality tools broadly promoted instruments in scientific literature - for the analysis and generation of action plans for improving the students' perspective of quality engineering education.

In conclusion, it is worth underscoring that the objective proposed in this study was to adapt the SERVQUAL scale to the Higher education service activity and to present the results of its application in an engineering institution, and it was appropriately met.

\section{REFERENCES}

[1] Badri, M. A.; Abdulla, M.; Al-Madani, A. 2005. "Information technology center service quality", International Journal of Quality \& Reliability Management, vol. 22(8), pp. 819-848. 
[2] Bannerjee, R. and Muley, V.P. 2007. "Engineering education in India”, report for Energy Systems Engineering, IITBombay.

[3] Bateson, J. E. G. and Hoffman, K. D. 2001. "Marketing of services", 4. ed. Porto Alegre: Bookman, Brazil.

[4] Brooks, R.F., Lings, I.N. and Botschen, M.A. 1999. "Internal marketing and customer driven wavefronts", Service Industries Journal, Vol. 19(4), pp. 49-67.

[5] Chaston, I., 1994, "Internal customer management and service gaps within the UK manufacturing sector", International Journal of Operations and Production, Vol. 149, pp. 45-56.

[6] Coelho, C. D. A., 2004, "Evaluation of the perceived quality services: an application private school for elementary and high school", Florianópolis, dissertation Master's Degree in Production Engineering Graduate Program in Engineering Production, Federal University of Santa Catarina.

[7] Cronbach, L.J. 1951, "Coefficient alpha and the internal structure of test", Psychometrica, Vol. 16, pp. 297-300.

[8] Cronin, J.J., and Taylor, S.A., 1992, "Measuring service quality: a re-examination and extension", Journal of Marketing, Vol. 56, pp. 55-68.

[9] Cronin, J.J., and Taylor, S.A., 1994, "SERVPERF versus SERVQUAL: reconciling performance-based and perceptions-minus-expectations measurement of service quality", Journal of Marketing, Vol. 58 January, pp. 125-31.

[10] Edvardsson, B., Larsson, G. and Setterlind, S. 1997, "Internal service quality and the psychological work environment: an empirical analysis of conceptual interrelatedness”, Service Industries Journal, Vol. 172, pp. $252-63$.

[11] Fitzsimmons, J.A., and Fitzsimmons, M.J., 2001, "Service Management, Operation Strategy and Technology Strategy", New York, Mc.Graw Hill.

[12] Grönroos, C., 2006, "Adopting a service logic for marketing”, Marketing theory, Vol.63, pp. 317-333.

[13] Interim report: Sarkar Committee, 1945. Higher technical institutions for the post-war industrial development, National Archives, New Delhi.

[14] Lings, I.N. and Brooks, R.F. 1998, "Implementing and measuring the effectiveness of internal marketing", Journal of Marketing Management, Vol. 14, pp. 325-51.

[15] Lovelock, C., 2001, "Services marketing - people, technology, strategy", $2^{\text {nd }}$ edition, upper Saddle River, Prentice Hall.

[16] Nunnally, J.C., 1978, "Psychometric Theory", McGraw Hill, New York, NY.

[17] Oliveira, O.J.D, and Ferreira, E.C., 2009, "Adaptation and application of the SERVQUAL scale in higher education", POMS 20th Annual Conference, Orlando, Florida,U.S.A.

[18] Owlia, M.S. and Aspinwall, E.M. 1998, "A framework for measuring quality in engineering education", Total Quality Management, Vol. 96, pp.501-518.

[19] Parasuraman, A., Berry, L. and Zeithaml, V., 1988, "SERVQUAL: a multiple item scale for measuring consumer perceptions of service quality", Journal of Retailing, Vol. 6419, pp. 420-450.

[20] Parasuraman, A., Berry, L.L., and Zeithaml, V.A., 1994, "Reassessment of expectations as a comparison standard in measuring service quality implications for future research", Journal of Marketing, Vol. 58, January, p. 111-124.

[21] Parasuraman, A., Zeithaml, V.A. and Berry, L.L., 1985, "A conceptual model of service quality and its implications for future research", Journal of Marketing, Vol. 494, pp. 41-50.

[22] Parasuraman, A., Zeithaml, V.A., and Berry, L.L., 1994, "Alternative scales for measuring service quality: a comparative assessment based on psychometric and diagnostic criteria", Journal of Retailing, Vol. 703, pp. 201-30.

[23] Reynoso, J. and Moore, B. 1995, "Towards the measurement of internal service quality", International Journal of Service Industry Management, Vol. 63, pp. 64-83.

[24] Sahney, S., Banwet, D.K., and Karunes, S. 2004, "A SERVQUAL and QFD approach to total quality education: A student perspective", International Journal of Productivity and Performance Management, Vol.53 2, pp. 143-166.

[25] Sahney, S., Banwet, D.K., and Karunes, S., 2008, "An Integrated Framework of Indices for Quality Management in Education: A Faculty Perspective”, The TQM Journal, Vol. 205, pp. 502-519.

[26] Salome, G. G. E., and MICHAEL, P. A. C., 2005 "SERVQUAL X Servperf: a comparison between instruments for assessing the quality of internal services", Production Management, Vol. 122, May / August, pp. 279-283.

[27] Teas, R.K., 1993, "Expectations, performance evaluation and consumer's perception of quality", Journal of Marketing, Vol. 5710, pp. 18-34.

[28] Teas, R.K., 1994, "Expectations as a comparison standard in measurement of service quality: an assessment of a reassessment", Journal of Marketing, Vol. 58, No. 1, January pp. 132-139.

[29] Young, J.A., and Varble, D.L., 1997, "Purchasing performance as seen by its internal customers: A study in a service organization", Journal of supply chain management, Vol 333, pp. 36-41.

[30] Zanella, A., Lima, L. S., And Lopes, L. F. D., 2006, "Identification of factors that influence in customer satisfaction of a recreational club by means of factor analysis", GEPRO Magazine, vol. 12, January/April.

[31] Zeithaml, V.A., Parasuraman, A., and Berry, L.L., 1985, "Problems and strategies in services marketing", Journal of Marketing, Vol. 49, Spring, pp. 33-46.

[32] Zeithaml, V.A., Parasuraman, A., and Berry, L.L., 1990, "Delivering quality service; Balancing customer perceptions and expectations", The Free Press, New York, NY. 


\section{Author' biography}

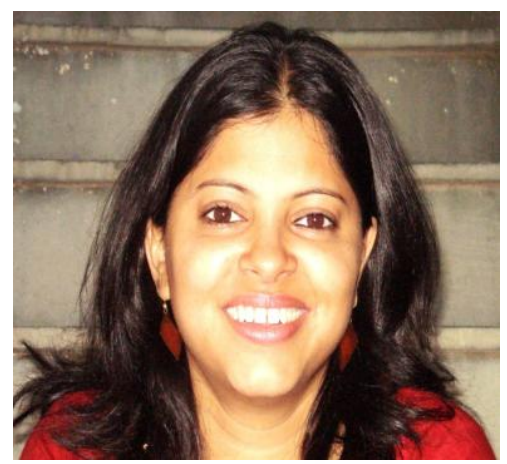

Dr. Santoshi Sengupta

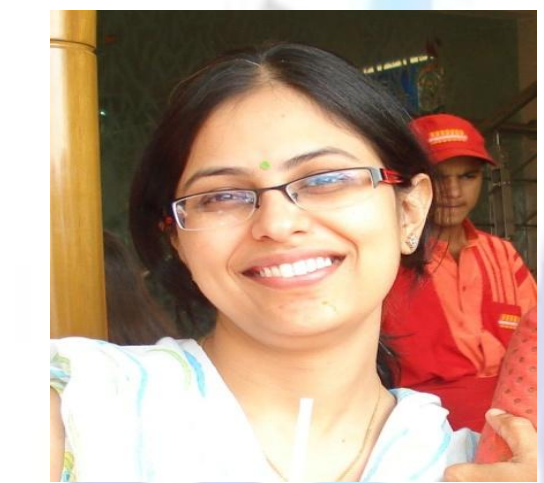

Dr. Arpita Sharma
Dr. Santoshi Sengupta, Ph.D in Management, has been working with Jaypee Institute of Information Technology JIIT, Noida, for the past six years. She started her career in January 2005 as a faculty in Department of Humanities and Social Sciences here in JIIT. She did her Post Doctoral studies from Universitat Pompeu Fabra, where she taught Social Psychology of Organizations and Psychology and business. She also worked with eminent researchers in the field of organization studies. She has to her credit around ten research publications in international and national journals of repute and also as chapters in books. She has presented a number of papers in international conferences both in India and abroad. She teaches Organization Behaviour, Total Quality Management, Presentation and Communication Skills, English and Group and Co-operative Processes to graduate and post graduate students. She endeavours to augment herself as a committed researcher and a proficient teacher to impart the best to students. She is a highly motivated, inventive and result - oriented academician, who seeks to coalesce academic training in a learning centric approach.

Dr. Arpita Sharma, a Ph.D in Management, is a committed academician and devoted researcher. She has to her credit a vivid experience in teaching under graduate and post graduate students for over 7 years. She started her career as a faculty in Professional Development Department with Jaypee Institute of Information Technology, Noida and then also spent some time with Jaipuria Institute of Management, Noida. She is currently based in US now, where she is doing research independently. She has published around 5 research papers in international and national journals of repute. She has presented a number of papers in various conferences. Her areas of interest are Project Management, Financial Management and Presentation and Communication Skills. She is a highly motivated, innovative and result - oriented educator, seeking to combine academic training in a learning centric approach to make a solid contribution to organizational goals in higher education. 